Research Article

\title{
Compression Characteristics of Solid Wastes as Backfill Materials
}

\author{
Meng Li, Jixiong Zhang, and Rui Gao \\ Key Laboratory of Deep Coal Resource Mining, School of Mines, Ministry of Education of China, \\ China University of Mining \& Technology, Xuzhou 221116, China
}

Correspondence should be addressed to Jixiong Zhang; zjxiong@cumt.edu.cn

Received 24 September 2015; Revised 15 January 2016; Accepted 2 March 2016

Academic Editor: Cristina Leonelli

Copyright (C) 2016 Meng Li et al. This is an open access article distributed under the Creative Commons Attribution License, which permits unrestricted use, distribution, and reproduction in any medium, provided the original work is properly cited.

\begin{abstract}
A self-made large-diameter compression steel chamber and a SANS material testing machine were chosen to perform a series of compression tests in order to fully understand the compression characteristics of differently graded filling gangue samples. The relationship between the stress-deformation modulus and stress-compression degree was analyzed comparatively. The results showed that, during compression, the deformation modulus of gangue grew linearly with stress, the overall relationship between stress and compression degree was approximately nonlinear, and the deformation of gangue was rather large during the initial portion of the test. Gangue sample mixed with Talbot Formula provides the best deformation resistance capacity, followed by fully graded and single-graded gangue samples. For applications, with adjustment of the gradation of filling materials and optimal design of compacting equipment, surface subsidence may be better controlled.
\end{abstract}

\section{Introduction}

At present, coal is still the primary source of global energy. For example, in China, coal has already accounted for nearly $70 \%$ of the country's primary energy consumption since the year $2000[1,2]$. The exploitation of coal resources is accompanied by large amounts of waste materials such as gangue and fly ash. According to official statistics, the amount of deposited gangue in China has already reached more than 5.5 billion tons, increasing by $0.4-0.6$ billion tons annually, occupying an area of about 15,000 hectares [3,4]. With the exception of a few small-scale underground waste disposal operations, for example, backfill of abandoned chambers and roadways, most of this waste is usually stockpiled close to collieries $[5,6]$. This may result in nonproductive land and pose potential threats to air and water quality. It may also lead to failure of waste embankments. These problems could be alleviated by disposing of the waste underground [7-10]. In addition, an estimated 13.79 billion tons of coal reserves is trapped under buildings, railway, and water bodies, among which coal reserves under buildings account for 9.468 billion tons or $69 \%$ of total reserves. In some countries, partial mining methods such as room and pillar mining and strip mining have been successfully employed to extract these coal reserves, but with massive coal pillars left in the gob [11].

In recent years, a solid backfill mining technology has been developed to solve the existing problems described above. Such a technology utilizes specific backfill equipment and backfill techniques to convey gangue into the gob where the solid material is backfilled $[12,13]$. Gangue on the surface is transported to the underground part of the mine via a vertical feeding hole after having been successively crushed and screened. Usually, the wastes are stored temporarily in an underground bunker connected to the vertical feeding hole. When needed, the wastes are delivered to a working panel and backfilled into the gob area void space by the compactor at the back of the hydraulic support (generally, the compacting force of this compactor is $2 \mathrm{MPa}$ ), so that solid stowing can be realized. The backfill material used in this method is gangue due to its availability and low cost. The grain size of the backfill gangue is usually $0-50 \mathrm{~mm}$.

Field experiments show that the compression deformation characteristics of backfill materials could influence the deformation magnitude and the extent of overlying strata, which consequently dominate surface subsidence $[5,14,15]$. It is, therefore, important to study the basic compression 


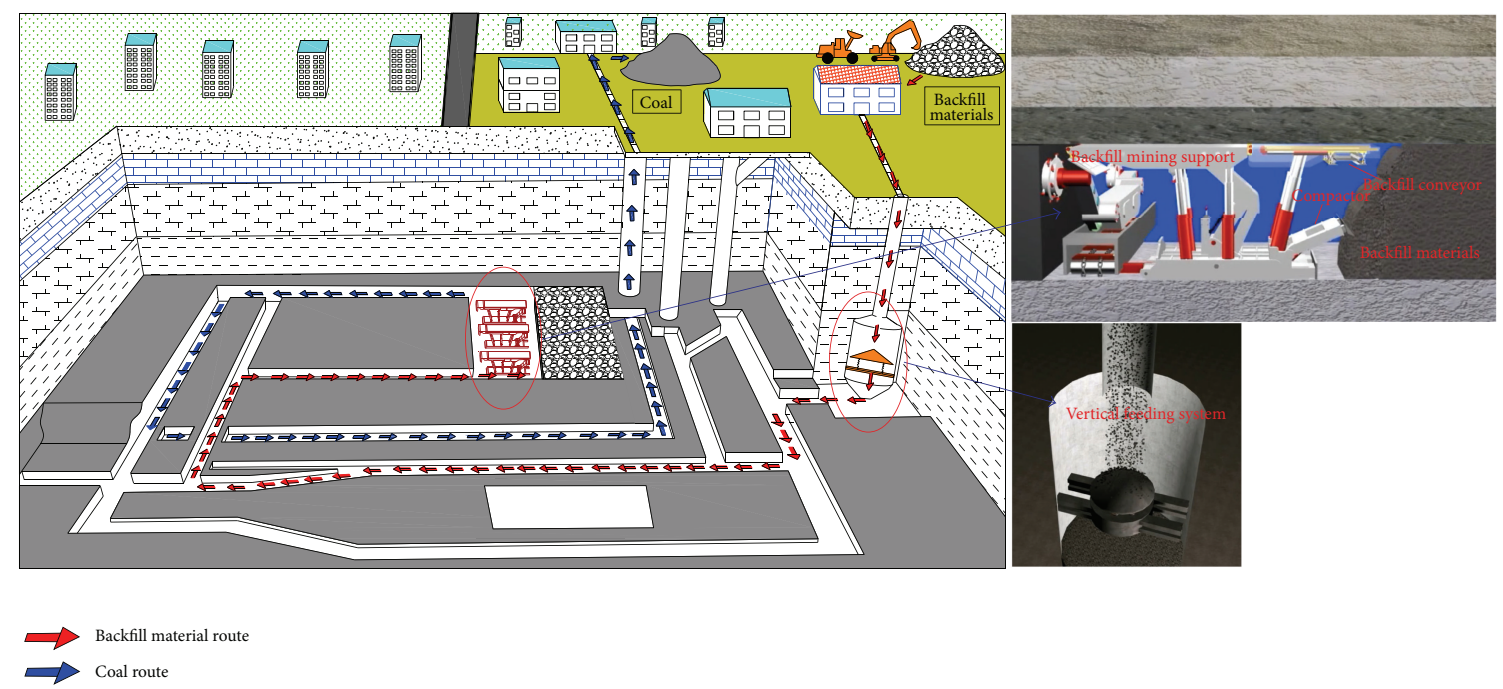

FIgURE 1: Basic principle of solid backfill mining.

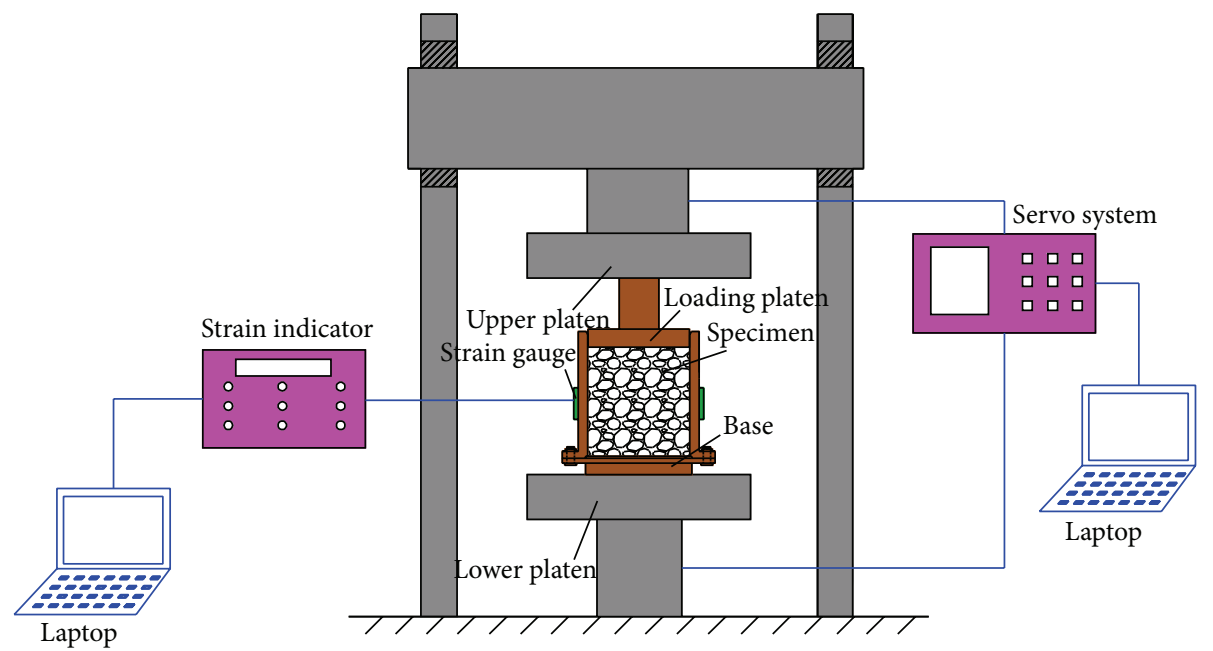

FIGURE 2: Schematic diagram of test system.

deformation characteristics of solid filling materials to better control surface deformation. In this paper, the relationships between stress and deformation modulus and between stress and compression degree were studied for gangue samples of different gradation, using a large-diameter compression steel chamber and a SANS material testing machine.

\section{Basic Principle of Solid Backfill Mining}

The basic principle of solid backfill mining is as shown in Figure 1. First, at the surface, the backfill material, such as gangue, is crushed to break it down to a grain size smaller than $50 \mathrm{~mm}$. The crushed material is transported through a vertical feeding system to an underground storage silo, from which, when required, it is moved to the backfill mining panel through an underground transportation system. Finally, through special devices on the backfill mining panel, the backfill material is filled into the gob, in which it produces a dense backfill, thus supporting the roof, reducing movement of the overlying strata, and controlling surface subsidence.

\section{Compression Test}

3.1. Test Materials. Solid materials were gangue samples from a coal preparation plant at the Changcun coal mine, Shanxi Lu'an Group. These gangue samples were fine sandstones with high hardness and sizes smaller than $50 \mathrm{~mm}$ which were sorted using sieves of the following sizes ( $\mathrm{mm}): 10,20,31.5,40$, and 50. In the collection process, the artificial destruction of the backfill material needed to be avoided as much as possible. Thus the test materials were all kept with their natural water content of $3.25 \%$; no other water was added during the test process.

3.2. Test Apparatus. Test system was comprised of a compression device and a testing machine, as shown in Figure 2. 


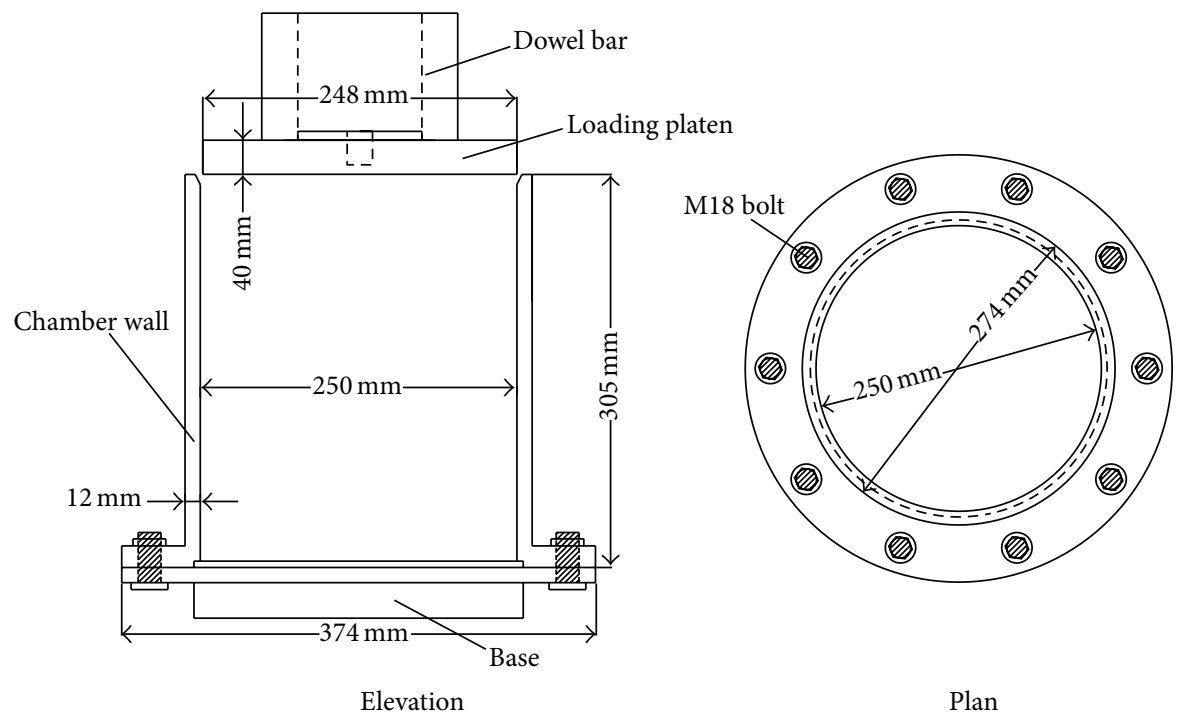

FIgURE 3: Plan and elevation views of compression device.

TABLE 1: Load deformation test series with different parameters.

\begin{tabular}{|c|c|c|c|c|c|c|}
\hline \multirow{2}{*}{ Category } & \multirow{2}{*}{ Test } & \multicolumn{5}{|c|}{ Percentage (by weight) } \\
\hline & & $50-40 \mathrm{~mm}$ & $40-31.5 \mathrm{~mm}$ & $31.5-20 \mathrm{~mm}$ & 20-10 mm & $10-0 \mathrm{~mm}$ \\
\hline \multirow{5}{*}{ Single-graded size } & 1 & 100 & & & & \\
\hline & 2 & & 100 & & & \\
\hline & 3 & & & 100 & & \\
\hline & 4 & & & & 100 & \\
\hline & 5 & & & & & 100 \\
\hline \multirow{4}{*}{ Maximum particle size } & 6 & & & & 46.3 & 53.7 \\
\hline & 7 & & & 40.3 & 27.6 & 32.1 \\
\hline & 8 & & 11.8 & 35.5 & 24.4 & 28.2 \\
\hline & 9 & 9.5 & 10.8 & 32.2 & 22.0 & 25.5 \\
\hline \multirow{4}{*}{ Full-scale gradation } & $10(n=0.3)$ & 6.5 & 7.7 & 9.8 & 14.3 & 61.7 \\
\hline & $11(n=0.4)$ & 8.5 & 10.0 & 12.2 & 16.8 & 52.5 \\
\hline & $12(n=0.5)$ & 10.6 & 11.9 & 14.3 & 18.5 & 44.7 \\
\hline & $13(n=0.6)$ & 12.5 & 13.9 & 15.9 & 19.6 & 38.1 \\
\hline
\end{tabular}

Note: $n$ is Talbot's exponent.

Since there are currently no standards for a granular material compression test, the compression device used in this test was self-made [16, 17], as shown in Figure 3. The test apparatus was composed of two parts: a steel chamber and a loading platen. The steel chamber was made out of $250 \mathrm{~mm}$ ID by $305 \mathrm{~mm}$ pipe with a thickness of $12 \mathrm{~mm}$. The loading platen consisted of $248 \mathrm{~mm}$ diameter by $40 \mathrm{~mm}$ thick steel plate. The clearance between the platen and the inside walls of the chamber was $1 \mathrm{~mm}$. The loading machine was a SANS material testing machine with a force loading speed ranging from 0.3 to $15 \mathrm{kN} / \mathrm{s}$, a displacement loading speed between 0 and $250 \mathrm{~mm} / \mathrm{s}$, and a stroke of 0 to $200 \mathrm{~mm}$. SANS is the leading manufacturer and supplier of static material testing instruments in China, which are capable of performing a full spectrum of material tests, including tension, shear, and compression. During the tests, the loading speed was set at $1 \mathrm{kN} / \mathrm{s}$ until a maximum load of $300 \mathrm{kN}$ was reached. The load and displacement were measured at $0.1 \mathrm{~s}$ intervals.

3.3. Test Schemes. These tests were designed to analyze the impacts of maximum grain size and grain size grading on the deformation characteristics of the samples in the process of compression. In China, for solid backfill mining, method of compaction testing of solid backfill materials issued by China National Energy Administration is used to guide the compaction laboratory tests [18]. Table 1 shows that the physical parameters varied during different compression tests. Tests 1-5 were designed to analyze the characteristic behavior of different single-graded gangue samples, while Tests 5-9 were used to examine the influence of maximum grain size on the compression characteristics. The gangue samples used in Tests 9-13 were all fully graded (smaller than $50 \mathrm{~mm}$ ) with different gradations. Tests 10-13 were prepared 
according to Talbot Theory. Talbot Theory has important implications for the design of material proportion. It is used to find the optimal ratio of the backfill materials, that is, which one is the least deformable. The Talbot Formula is defined by the following equation:

$$
p=100\left(\frac{d}{D}\right)^{n}
$$

where $p$ is the pass percentage of particles with radius smaller than $d$ and $D$ is the maximum grain size of the material.

During the tests, the gangue samples were placed in the compression device and the loading machine was used to compact the materials until the loading strength reaches the maximum load of $300 \mathrm{kN}$. Data were then collected to analyze the compression characteristics of the gangue samples.

\section{Test Results and Analysis}

4.1. Stress-Deformation Modulus Relationship. As a discrete medium, there is no applicable theory to accurately describe the mechanical properties of the constitutive relationship theory of gangue samples. To study this relationship in the process of compression, the deformation modulus $E$ is defined in

$$
\begin{aligned}
E & =\frac{\sigma}{\varepsilon}, \\
\varepsilon & =\frac{\Delta h}{h},
\end{aligned}
$$

where $\sigma$ is the compression stress, $\Delta h$ is the cumulative displacement of the material, and $h$ is the initial height of the test material.

The relationship between stress and deformation modulus for Tests 1-13 is shown in Figure 4.

For all of the gangue samples, a strong, positive linear correlation between deformation modulus and stress is observed. Under the same compacting strength, the deformation modulus of Tests $1-13$ was in the order $n=0.4>$ $n=0.3>n=0.5>n=0.6$ (similarly with $0-40 \mathrm{~mm}$ ) $>$ original sample (similarly with $0-31.5 \mathrm{~mm}$ and $0-20 \mathrm{~mm}$ ) $>0-10 \mathrm{~mm}>10-20 \mathrm{~mm}>20-31.5 \mathrm{~mm}>31.5-40 \mathrm{~mm}>40-$ $50 \mathrm{~mm}$. This implies that the gangue samples with Talbot's grading have a higher deformation modulus, followed by the maximum particle gangue and the single-graded size. This suggests that the gangue graded by Talbot's exponent could be nondeformable to a large degree. Talbot's grading guarantees a perfect gap and matching in the gangue samples, which could provide good resistance to deformation.

In view of the stress-deformation modulus relationships of all of the tests above, the deformation moduli corresponding to stresses of 2 and $12.5 \mathrm{MPa}$ were also obtained (Table 2).

Based on the data given in Table 2 and the stressdeformation curve in Figure 4, the following were concluded: (a) the stress-deformation modulus relationships of all tests are linear; that is, the deformation modulus increases with increasing stress; (b) generally, the deformation modulus of fully graded gangue is higher than that for gangue with

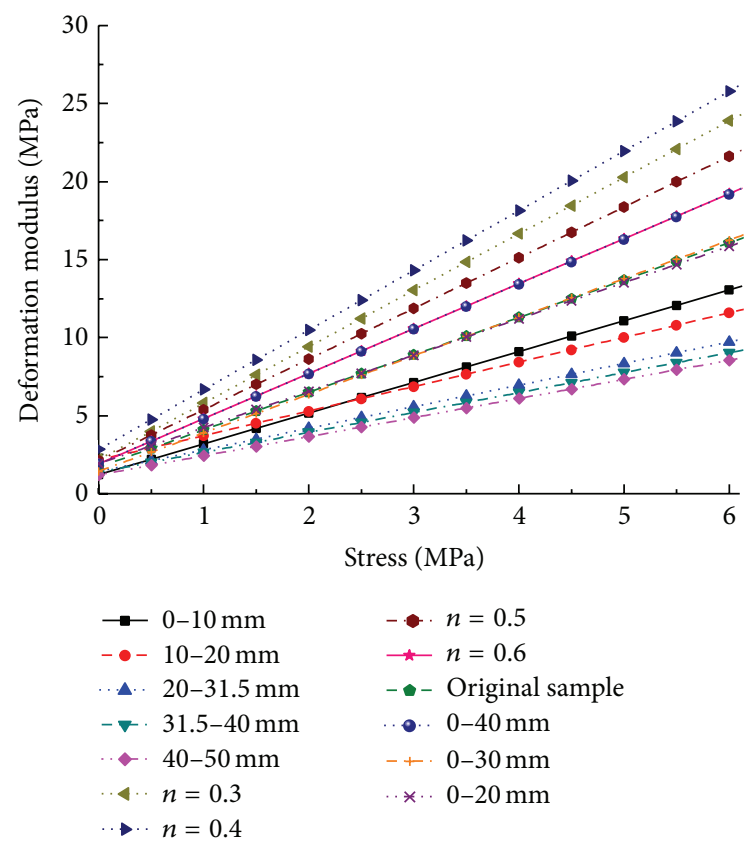

FIGURE 4: Stress versus deformation modulus for all graded samples.

the maximum grain size, while the deformation modulus of the gangue with the maximum grain size is higher than that for single-graded gangue. In other words, full-scale grading can result in speeding up the process of compacting backfill materials. In terms of controlling the movement and subsidence of the roof in the gob area, this is the optimal scheme.

4.2. Stress-Compression Degree Relationship. The compression degree of gangue samples can reflect their resistance to deformation. The compression degree $k$ is defined by the following equation:

$$
k=\frac{h-\Delta h}{h}=1-\frac{\Delta h}{h}=1-\varepsilon,
$$

where $\Delta h$ is the cumulative displacement of the material and $h$ is the initial height of the test material.

The stress-compression degree curves for Tests 1-13 were obtained by fitting the experimental data, as shown in Figures 5-7.

It can be seen from Figure 5 and the fitting function that (1) the stress-compression degree curves of single-sized gangue samples 1-5 were nonlinear. During the initial stage of the test $(0-2 \mathrm{MPa})$, the decrement in the compression degree was large and the compression proceeded rapidly. As the stress continued to increase and the gangue was further compacted, the decrement in the compression degree decreased, and this tended to be stable; (2) under the same level of compacting strength, the compression degree of Tests $1-5$ was $0-10 \mathrm{~mm}>10-20 \mathrm{~mm}>20-30 \mathrm{~mm}>30-40 \mathrm{~mm}>$ $40-50 \mathrm{~mm}$. This is because the void ratio of $0-10 \mathrm{~mm}$ gangue sample was relatively low and the compression of gangue was therefore smaller, resulting in a higher nondeformability. 
TABLE 2: Summary of deformation modulus-stress test results.

\begin{tabular}{|c|c|c|c|c|}
\hline \multirow{2}{*}{ Category } & \multirow{2}{*}{ Test } & \multicolumn{3}{|c|}{ Deformation modulus/MPa } \\
\hline & & Stress of $2 \mathrm{MPa}$ & Stress of $12.5 \mathrm{MPa}$ & 2-12.5 MPa increments \\
\hline \multirow{5}{*}{ Single-graded size } & 1 & 3.65 & 16.50 & 12.85 \\
\hline & 2 & 3.93 & 17.33 & 13.40 \\
\hline & 3 & 4.19 & 18.71 & 14.52 \\
\hline & 4 & 5.30 & 21.81 & 16.51 \\
\hline & 5 & 5.17 & 25.87 & 20.70 \\
\hline \multirow{4}{*}{ Maximum particle size } & 6 & 6.56 & 30.94 & 24.38 \\
\hline & 7 & 6.37 & 32.32 & 25.95 \\
\hline & 8 & 7.68 & 37.87 & 30.19 \\
\hline & 9 & 6.49 & 31.68 & 25.19 \\
\hline \multirow{4}{*}{ Full-scale gradation } & $10(n=0.3)$ & 9.42 & 47.41 & 37.99 \\
\hline & $11(n=0.4)$ & 10.49 & 50.63 & 40.14 \\
\hline & $12(n=0.5)$ & 8.63 & 42.72 & 34.09 \\
\hline & $13(n=0.6)$ & 7.69 & 37.99 & 30.30 \\
\hline
\end{tabular}

Note: $n$ is Talbot's exponent.

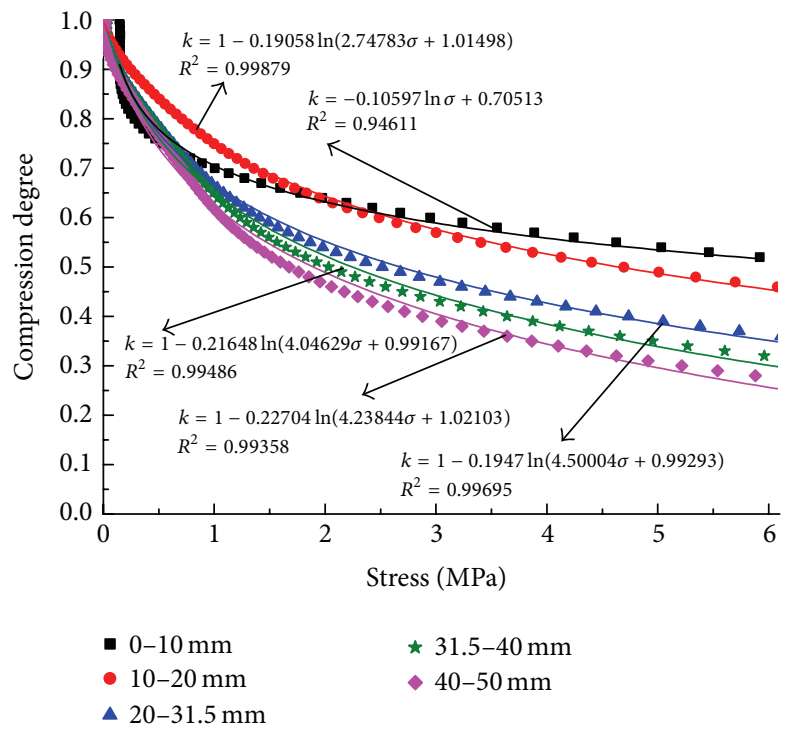

FIGURE 5: Stress-compression degree for single-graded samples.

From Figure 6 and the fitting function, the following were found: (1) the stress-compression degree curves of gangue samples 5-9 with maximum grain size were nonlinear. During the initial stage of the test $(0-2 \mathrm{MPa})$, the decrement in the compression degree was large and the compression proceeded rapidly. As the stress increased and the gangue was further compacted, the compression degree of the samples decreased and finally stabilized; (2) under the same level of compacting strength, the sample of $0-40 \mathrm{~mm}$ with respect to compression degree of Tests 5-9 was the best, while the sample of $0 \sim 10 \mathrm{~mm}$ was the worst. The compression degrees of samples 0-20 mm, 0-31.5 mm, and 0 50 mm were similar to each other. This is because the destroyed fragments can better refill the rest of the gap inside the sample of $0-40 \mathrm{~mm}$ after compression and crushing, resulting in a lower void ratio

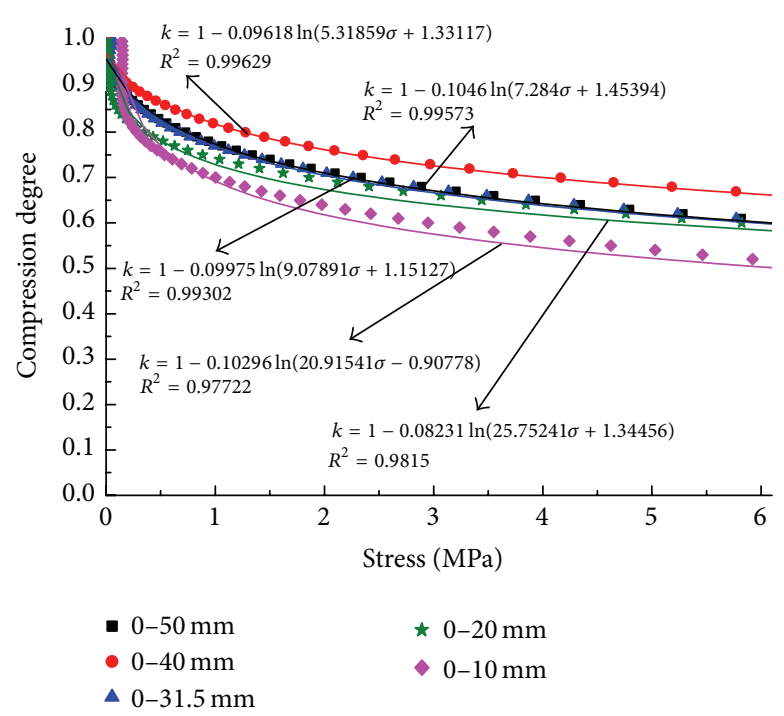

FIGURE 6: Stress-compression degree for maximum grain size samples.

than the other samples. This led to an increased compression degree and nondeformability.

From Figure 7 and the fitting function, the following were found: (1) the stress-compression degree curves of fully graded gangue schemes 9-13 were nonlinear and generally varied similarly to the pattern of Tests 1-9 described above; (2) under the same level of compacting strength, the compression degree of Tests 9-13 (Talbot's exponent $n$ is used to represent the test scheme) was $n=0.4>n=0.3>n=0.5>$ $n=0.6>$ original sample. As shown in Figure 6, the gangue sample for $n=0.4$ had a better grading and could better refill the void space after compression and crushing, resulting in a higher resistance to deformation and compression degree.

Examining all stress-compression degree relationships above, we found the compression degree when the 
TABLE 3: Summary of compression degree-stress test results.

\begin{tabular}{|c|c|c|c|c|}
\hline \multirow{2}{*}{ Category } & \multirow{2}{*}{ Test } & \multicolumn{3}{|c|}{ Compression degree } \\
\hline & & Stress of $2 \mathrm{MPa}$ & Stress of $12.5 \mathrm{MPa}$ & $2 \sim 12.5 \mathrm{MPa}$ increments \\
\hline \multirow{5}{*}{ Single size } & 1 & 0.4246 & 0.1493 & 0.28 \\
\hline & 2 & 0.4630 & 0.1958 & 0.27 \\
\hline & 3 & 0.5011 & 0.2427 & 0.26 \\
\hline & 4 & 0.5991 & 0.3451 & 0.25 \\
\hline & 5 & 0.6168 & 0.4166 & 0.20 \\
\hline \multirow{4}{*}{ Maximum particle size } & 6 & 0.6770 & 0.5131 & 0.16 \\
\hline & 7 & 0.6910 & 0.5245 & 0.17 \\
\hline & 8 & 0.7448 & 0.5934 & 0.15 \\
\hline & 9 & 0.6936 & 0.5247 & 0.17 \\
\hline \multirow{4}{*}{ Full-scale gradation } & $10(n=0.3)$ & 0.8051 & 0.6721 & 0.13 \\
\hline & $11(n=0.4)$ & 0.8245 & 0.6926 & 0.13 \\
\hline & $12(n=0.5)$ & 0.7832 & 0.6458 & 0.14 \\
\hline & $13(n=0.6)$ & 0.7423 & 0.5996 & 0.14 \\
\hline
\end{tabular}

Note: $n$ is Talbot's exponent.

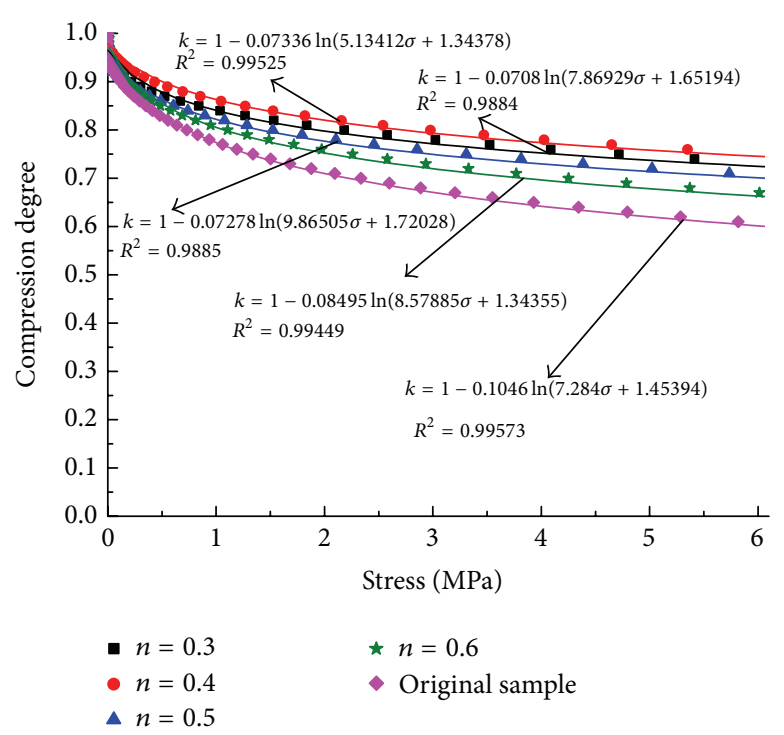

FIGURE 7: Stress-compression degree for full-scale graded samples.

compacting force was $2 \mathrm{MPa}$ and the stress of primary rock was $12.5 \mathrm{MPa}$. The details are given in Table 3 .

Based on the data in Table 3 and all stress-compression degree curves, the following can be concluded: (a) the stresscompression degree relationships of the three schemes share a similar trend, which is composed of three stages: rapid compression, slow compression, and gradual stabilization; (b) generally, the compression degrees of fully graded gangue, gangue with maximum grain size, and single-graded gangue are in descending order. The compression degree of fully graded gangue shows the minimum change between 2 and 12.5 MPa; that is, the materials have the optimal resistance to pressure and are the best for backfill and controlling the roof in gob areas. When the initial compacting force is around $2 \mathrm{MPa}$, it is able to compact backfill materials rapidly and ensure the supporting intensity of gangue; and (c) during the initial compression period ( $0-2 \mathrm{MPa})$, loose gangue samples under compressive stress showed such characteristics that gaps between gangue samples were quickly filled. The greater the compression, the lower the nondeformability. As the compressive stress increased from 2 to $15 \mathrm{MPa}$, gangue samples were destroyed again and the destroyed fragments refilled the rest of the gaps, which reduced the void ratio of the gangue sample and increased its nondeformability. As the compressive stress increased further, the gaps were fully filled and the gangue was evenly stressed, which stabilized the compression degree of the gangue sample and enhanced its nondeformability.

As described above, it was found that the gangue samples with Talbot's exponent had the best nondeformability. This is because Talbot's exponent sample is perfectly matched to the different sizes of gangue samples and makes for a smooth gradation curve and a uniform sample, which caused the stress-compression curve to decrease by at least $16.7 \%$ compared with the other grading samples. This shows that gangue samples graded by means of Talbot exponent have good backfill properties, which is important for mining and backfill.

\section{Conclusions}

(1) During the compression period, the deformation modulus of gangue samples increased linearly with increase in stress, while the stress-compression degree relationship was nonlinear.

(2) The relationship between stress and compression degree for the three test schemes was similar and could be roughly divided into three stages. When the stress was $0-2 \mathrm{MPa}$ (initial stage), the void ratio of the gangue sample was relatively large and the compression amount of samples presents the largest and most rapid change. Most of the deformation occurred at this stage. When the stress is $2-12.5 \mathrm{MPa}$, the samples 
were compacted slowly. The broken gangue gradually refilled the rest of the space, indicating a slight variation in compression degree. Furthermore, as the stress increased further, the compression degree tended to stabilize and the void ratio was lower.

(3) At the same stress level, samples graded using Talbot's Formula provided the best resistance to deformation, followed by the fully graded gangue sample and the single-graded gangue sample. This is consistent with the smooth gradation curve and the uniformity of the sample.

(4) In practical engineering applications, most of the deformation of the compacted gangue occurs in the initial stage. Therefore, the amount of deformation can be reduced after backfill based on optimal compression agencies and compression force. In addition, grading of gangue to a large extent determines the deformation of the material. Materials with strong resistance to deformation can be obtained by adjusting the grading.

\section{Competing Interests}

The authors declare that there are no competing interests regarding the publication of this paper.

\section{Acknowledgments}

This work was supported by Qing Lan Project, Jiangsu Province, and State Key Laboratory of Coal Resources and Safe Mining, CUMT, under Grant SKLCRSM12X01.

\section{References}

[1] M.-G. Qian, X.-X. Miao, and J.-L. Xu, "Green mining of coal resources harmonizing with environment," Journal of the China Coal Society, vol. 32, no. 1, pp. 1-7, 2007.

[2] J. X. Zhang, H. Q. Jiang, X. J. Deng, and F. Ju, "Prediction of the height of the water-conducting zone above the mined panel in solid backfill mining," Mine Water and the Environment, vol. 33, no. 4, pp. 317-326, 2014.

[3] J. M. Xu, J. X. Zhang, Y. L. Huang, and F. Ju, "Experimental research on the compress deformation characteristic of wastefly ash and its application in backfill fully mechanized coal mining technology," Journal of Mining \& Safety Engineering, vol. 26, no. 1, pp. 158-162, 2011.

[4] Y. L. Huang, J. X. Zhang, Q. Zhang, and S. J. Nie, "Backfill technology of substituting waste and fly ash for coal underground in China coal mining area," Environmental Engineering and Management Journal, vol. 10, no. 6, pp. 769-775, 2011.

[5] M. G. Karfakis, C. H. Bowman, and E. Topuz, "Characterization of coal-mine refuse as backfilling material," Geotechnical and Geological Engineering, vol. 14, no. 2, pp. 129-150, 1996.

[6] K. M. Skarzyńska, "Reuse of coal mining wastes in civil engineering. Part 1. Properties of minestone," Waste Management, vol. 15, no. 1, pp. 3-42, 1995.

[7] Q. Zhang, J. Zhang, Y. Huang, and F. Ju, "Backfilling technology and strata behaviors in fully mechanized coal mining working face," International Journal of Mining Science and Technology, vol. 22, no. 2, pp. 151-157, 2012.

[8] M. Junker and H. Witthaus, "Progress in the research and application of coal mining with stowing," International Journal of Mining Science and Technology, vol. 23, no. 1, pp. 7-12, 2013.

[9] G. W. Fan, D. S. Zhang, and X. F. Wang, "Reduction and utilization of coal mine waste rock in China: a case study in Tiefa coalfield," Resources, Conservation and Recycling, vol. 83, pp. 792-798, 2014.

[10] D.-M. Tian, J. Yao, Z.-A. Jiang, X.-M. Wang, and Q.-L. Zhang, "The experimental study of the coal gangue as gel filling materials," Journal of Coal Science and Engineering, vol. 14, no. 1, pp. 125-130, 2008.

[11] X.-X. Miao and M.-G. Qian, "Research on green mining of coal resources in China: current status and future prospects," Journal of Mining \& Safety Engineering, vol. 26, no. 1, pp. 1-14, 2009.

[12] M. Li, J. X. Zhang, and X. X. Miao, "Experimental investigation on compaction properties of solid backfill materials," Mining Technology: Transactions of the Institutions of Mining and Metallurgy: Section A, vol. 123, no. 4, pp. 193-198, 2014.

[13] N. Zhou, H. Q. Jiang, and J. X. Zhang, "Application of solid backfill mining techniques for coal mine under embankment dam," Mining Technology: Transactions of the Institutions of Mining and Metallurgy Section A, vol. 122, no. 4, pp. 228-234, 2013.

[14] H. Yavuz, "An estimation method for cover pressure reestablishment distance and pressure distribution in the goaf of longwall coal mines," International Journal of Rock Mechanics and Mining Sciences, vol. 41, no. 2, pp. 193-205, 2004.

[15] G.-L. Guo, X.-J. Zhu, J.-F. Zha, and Q. Wang, "Subsidence prediction method based on equivalent mining height theory for solid backfilling mining," Transactions of Nonferrous Metals Society of China, vol. 24, no. 10, pp. 3302-3308, 2014.

[16] D. M. Pappas and C. Mark, "Behavior of simulated longwall gob material," Report of Investigations, Bureau of Mines, Washington, DC, USA, 1993.

[17] Z. Y. Ti, H. Y. Qin, and S. X. Li, "Experimental analysis of compaction characteristics filled by coal gangue," Journal of Water Resources \& Water Engineering, vol. 23, no. 4, pp. 129-131, 2012.

[18] National Energy Administration, Method of Compaction Testing of Solid Backfill Materials, China Energy Industry Standard, Shanghai, China, 2014. 

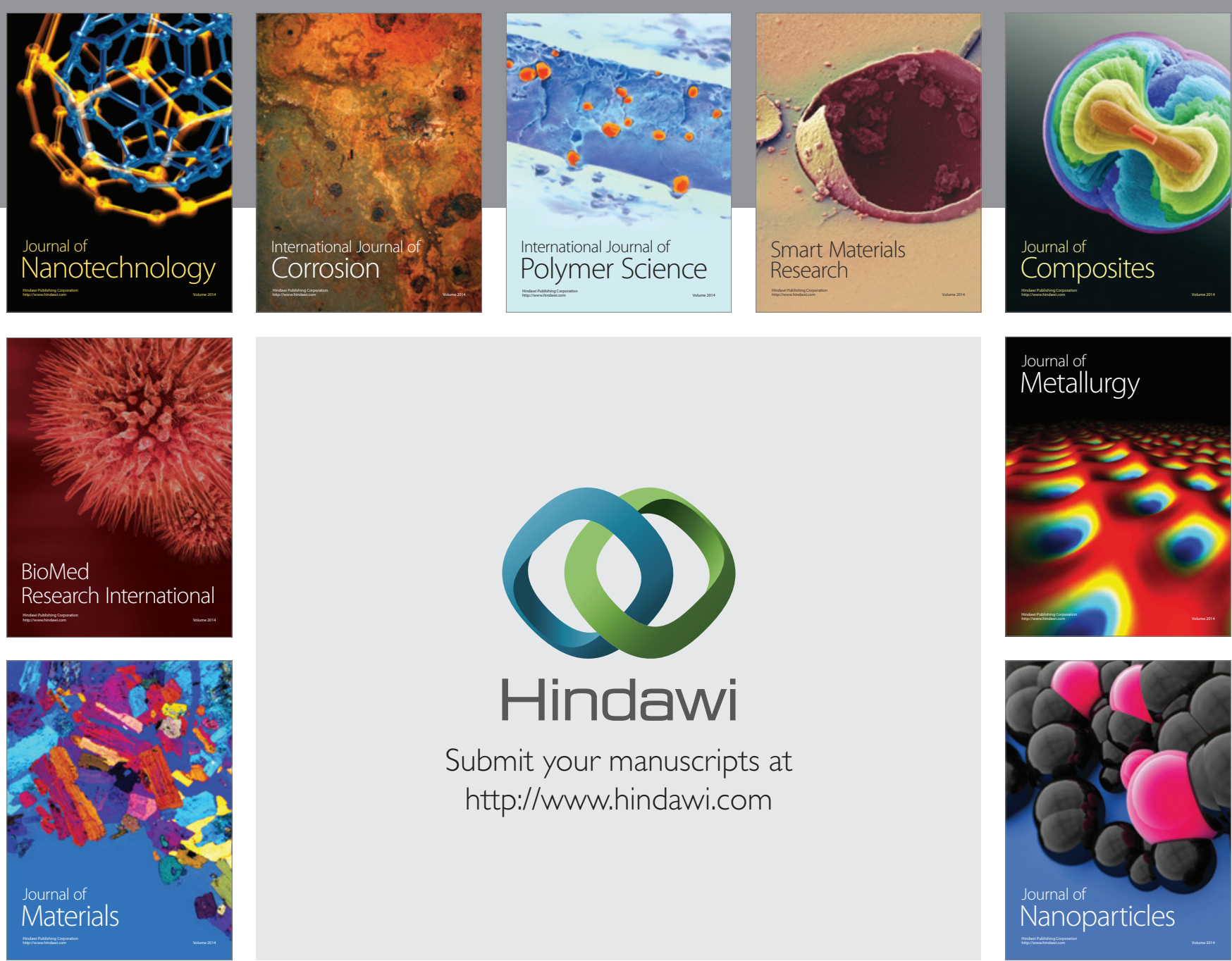

\section{Hindawi}

Submit your manuscripts at

http://www.hindawi.com

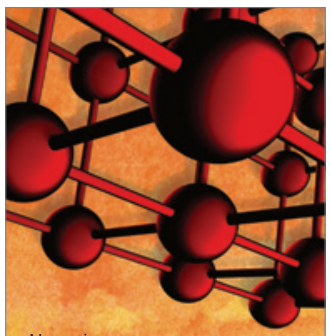

Materials Science and Engineering
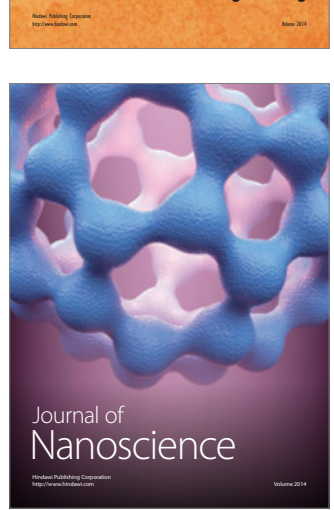
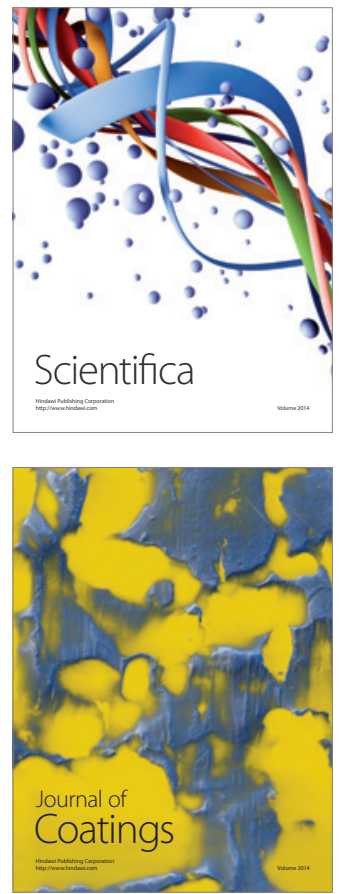
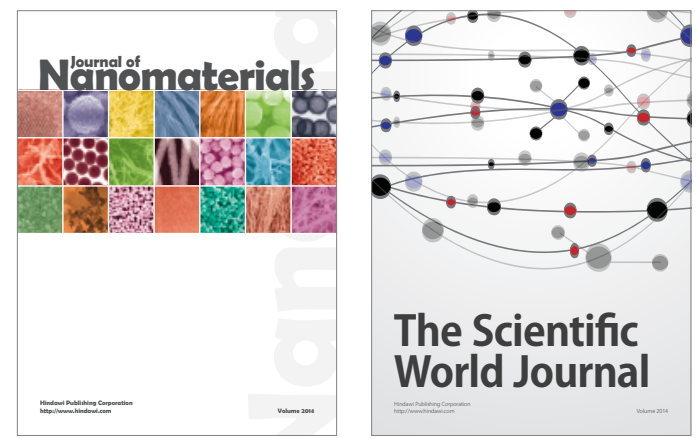

The Scientific World Journal
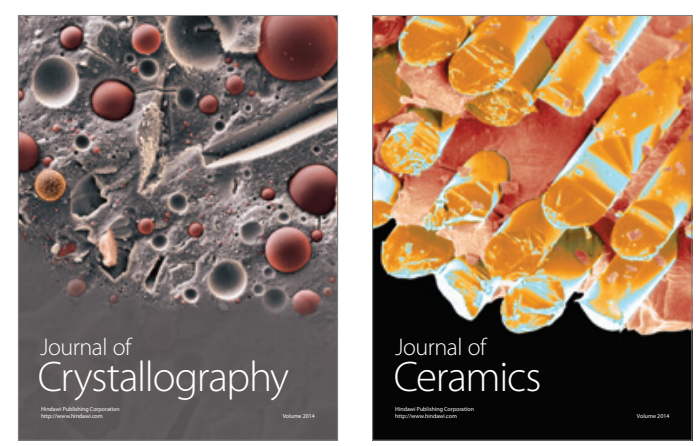
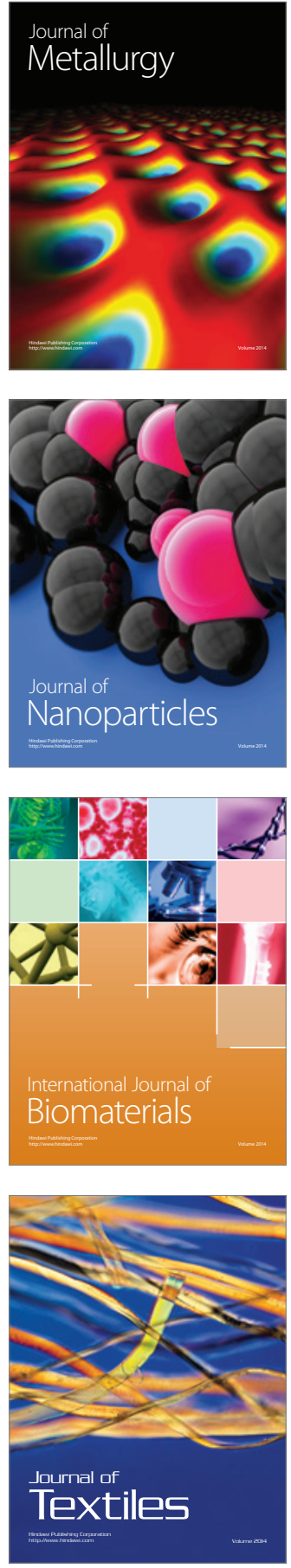